\title{
ANALISIS PERBANDINGAN \\ RENCANA ANGGARAN BIAYA BERDASARKAN METODE SNI DENGAN PERHITUNGAN KONTRAKTOR
}

\author{
Kharisma Permata Sari ${ }^{1}$, Utami Dewi Arman ${ }^{2}$, Muhammad Ridwan ${ }^{3}$ \\ ${ }^{1}$ Fakultas Teknik, Universitas Putra Indonesia "YPTK", Padang \\ ${ }^{2}$ Fakultas Teknik, Universitas Putra Indonesia "YPTK", Padang \\ ${ }^{3}$ Fakultas Teknik, Universitas Putra Indonesia "YPTK", Padang
}

\begin{abstract}
Budgeting is one of the main processes in a project because it is the basis for making a payment system offer and an estimation framework to be issued. This study aims to determine the comparison and estimation results that are more economical than calculations according to the Contractor with the SNI method on the construction work of the Service House Type 90. The data collection method used in this research is secondary data, namely by obtaining data on the wages of workers and materials. / material from the Contractor, and also from the SNI Guidelines, based on the results of the analysis of the calculation of the budget plan for the construction of an Official House Type 90, it is obtained that the budget using the SNI Method is Rp. 434,036,466.44 and the Calculation Method according to the Contractor is Rp. The price difference from the calculation using the SNI method with the calculation according to the Contractor is IDR 20,994,069.97, and for the percentage difference the calculation is $4.83 \%$. So that the calculation of the budget according to the contractor is more economical than the SNI method.
\end{abstract}

Keywords: Construction Cost Budget, SNI, Contractor, AHSP

\begin{abstract}
Abstrak
Rencana Anggaran Biaya (RAB) merupakan salah satu proses utama dalam suatu proyek karena merupakan dasar untuk membuat penawaran sistem pembayaran dan kerangka estimasi yang akan dikeluarkan. Penelitian ini bertujuan untuk mengetahui perbandingan dan hasil estimasi yang lebih ekonomis dari perhitungan menurut Kontraktor dengan metode SNI pada pekerjaan pembangunan Rumah Dinas Type 90. Metode Pengambilan data yang dilakukan dalam penelitian tugas akhir ini adalah dengan data Sekunder yaitu dengan mendapatkan data harga upah pekerja dan bahan/material dari Kontraktor, dan juga dari Pedoman SNI, berdasarkan hasil analisis perhitungan rencana anggaran biaya pembangunan Rumah Dinas Type 90, diperoleh anggaran biaya dengan Metode SNI sebesar Rp 434.036.466,44 dan Metode Perhitungan menurut Kontraktor sebesar Rp 413.042.396,47. Selisih harga dari perhitungan dengan menggunakan metode SNI dengan perhitungan menurut Kontraktor sebesar Rp 20.994.069,97, dan untuk persentase selisih perhitungannya adalah sebesar 4,83\%. Sehingga Perhitungan Anggaran Biaya Menurut Kontraktor lebih ekonomis dibandingkan dengan Metode SNI.
\end{abstract}

Kata kunci: Rencana Anggaran Biaya Konstruksi, SNI, Kontraktor, AHSP

\section{PENDAHULUAN}

Dalam sebuah proyek konstruksi, perkiraan biaya memegang peranan penting dalam penyelenggaraan proyek.
Pada tahap pertama dipergunakan untuk mengetahui berapa besar biaya yang diperlukan untuk membangun proyek atau investasi. Menurut Sastraatmadja, S, 1994, 


\section{Analisa Anggaran Biaya Pelaksanaan,} menerangkan bahwa untuk meningkatkan efisiensi dan efektivitas kegiatan pembangunan di bidang konstruksi, diperlukan suatu sarana dasar perhitungan harga satuan yaitu Analisa Biaya Konstruksi disingkat ABK adalah suatu cara perhitungan harga satuan pekerjaan konstruksi, yang dijabarkan dalam perkalian indeks bahan bangunan dan upah kerja dengan harga bahan bangunan dan standard pengupahan pekerja, untuk menyelesaikan persatuan pekerjaan konstruksi analisa biaya konstruksi yang selama ini dikenal yaitu analisa SNI. Kontraktor umumnya membuat harga penawaran berdasarkan analisa yang tidak seluruhnya berpedoman pada analisa SNI. Para kontraktor lebih cenderung menghitung harga satuan pekerjaan berdasarkan dengan analisa mereka sendiri yang didasarkan atas pengalaman terdahulu dalam menyelesaikan suatu pekerjaan konstruksi, walapun tidak terlepas dari SNI. Rencana Anggaran Biaya (RAB) merupakan salah satu proses utama dalam suatu proyek karena merupakan dasar untuk membuat penawaran system pembayaran dan kerangka estimasi yang akan dikeluarkan. Hal ini diperlukan untuk memperhitungkan suatu bangunan atau proyek dengan banyaknya biaya yang diperlukan untuk bahan dan upah, serta biaya-biaya lain yang berhubungan dengan pelaksanaan proyek.

\section{METODE PENELITIAN}

Metodologi dalam penelitian ini dapat di lihat dari Flowchart berikut ini :

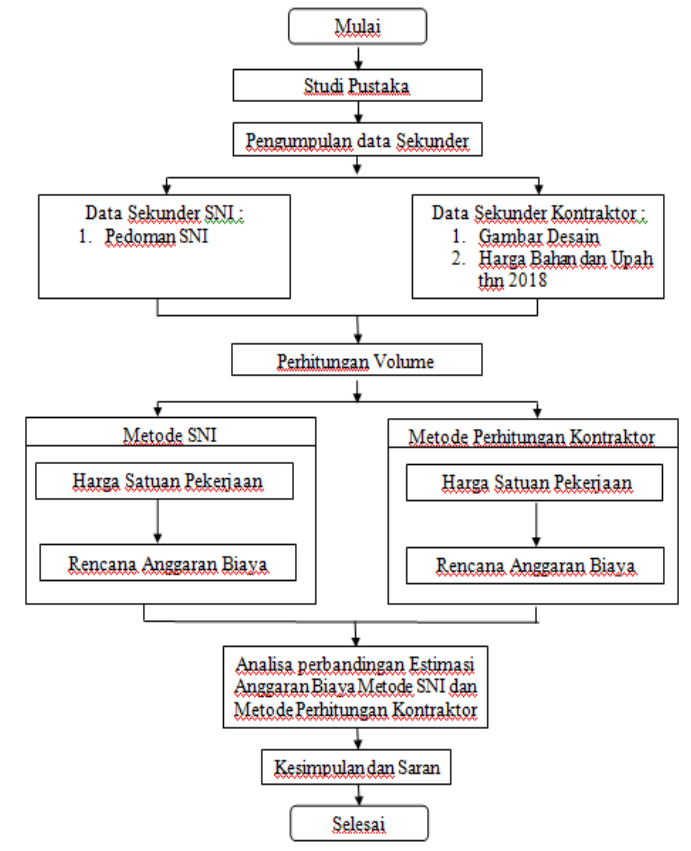

Gambar 1. Metodologi Penelitian

HASIL DAN PEMBAHASAN

\subsection{Daftar Rencana Anggaran} Biaya Metode SNI

Tabel 1 : Daftar Rencana Anggaran Biaya Metode SNI

\begin{tabular}{|c|c|c|c|c|c|}
\hline $\begin{array}{l}\mathbf{N} \\
\mathbf{o}\end{array}$ & Item Pekerjaan & $\mathbf{v}$ & $\mathbf{S}$ & $\begin{array}{c}\text { Harga } \\
\text { Satuan } \\
(\mathbf{R p}) \\
\end{array}$ & $\begin{array}{c}\text { Jumlah } \\
\text { Harga } \\
(\mathbf{R p}) \\
\end{array}$ \\
\hline $\mathbf{A}$ & Pekerjaan Persiapan & & & & \\
\hline 1 & Pembersihan Halaman & $\begin{array}{r}28 \\
8,0 \\
0 \\
\end{array}$ & $\begin{array}{l}\mathrm{M} \\
2\end{array}$ & $\begin{array}{r}10.407,5 \\
0 \\
\end{array}$ & $\begin{array}{r}2.997 .36 \\
0,00 \\
\end{array}$ \\
\hline 2 & $\begin{array}{l}\text { Pengukuran dan Pemasangan } \\
\text { Bowplank }\end{array}$ & $\begin{array}{r}51, \\
00 \\
\end{array}$ & M & $\begin{array}{r}286.779 \\
41 \\
\end{array}$ & $\begin{array}{r}14.625 .7 \\
49,91 \\
\end{array}$ \\
\hline \multicolumn{5}{|c|}{ Jumlah } & $\begin{array}{r}17.623 .1 \\
09,91 \\
\end{array}$ \\
\hline B & Pekerjaan Tanah & & & & \\
\hline 1 & $\begin{array}{l}\text { Galian Tanah Pondasi Batu } \\
\text { Kali }\end{array}$ & $\begin{array}{r}94, \\
20\end{array}$ & $\begin{array}{c}\mathrm{M} \\
3 \\
\end{array}$ & $\begin{array}{r}76.475,0 \\
0 \\
\end{array}$ & $\begin{array}{r}7.203 .94 \\
5,00 \\
\end{array}$ \\
\hline 2 & Urugan kembali & $\begin{array}{r}23, \\
64 \\
\end{array}$ & $\begin{array}{c}\mathrm{M} \\
3 \\
\end{array}$ & $\begin{array}{r}55.200,0 \\
0 \\
\end{array}$ & $\begin{array}{r}1.304 .92 \\
8,00 \\
\end{array}$ \\
\hline 3 & $\begin{array}{l}\text { Urugan Tanah untuk } \\
\text { Peninggian Muka Lantai }\end{array}$ & $\begin{array}{r}18, \\
84\end{array}$ & $\begin{array}{c}\mathrm{M} \\
3 \\
\end{array}$ & $\begin{array}{r}172.500, \\
00 \\
\end{array}$ & $\begin{array}{r}3.249 .90 \\
0,00 \\
\end{array}$ \\
\hline 4 & $\begin{array}{l}\text { Urugan Pasir Bawah Pondasi } \\
\text { Batu Kali, } \mathrm{t}=10 \mathrm{~cm}\end{array}$ & $\begin{array}{r}7,8 \\
5 \\
\end{array}$ & $\begin{array}{c}\mathrm{M} \\
3 \\
\end{array}$ & $\begin{array}{r}138.230, \\
00 \\
\end{array}$ & $\begin{array}{r}1.085 .10 \\
5,50 \\
\end{array}$ \\
\hline 5 & $\begin{array}{l}\text { Urugan Pasir Bawah Lantai t } \\
=5 \mathrm{~cm}\end{array}$ & $\begin{array}{r}3,9 \\
2 \\
\end{array}$ & $\begin{array}{c}\mathrm{M} \\
3 \\
\end{array}$ & $\begin{array}{r}138.230, \\
01 \\
\end{array}$ & $\begin{array}{r}541.861, \\
64 \\
\end{array}$ \\
\hline \multicolumn{5}{|c|}{ Jumlah } & $\begin{array}{r}13.385 .7 \\
40,14 \\
\end{array}$ \\
\hline $\mathrm{C}$ & $\begin{array}{l}\text { Pekerjaan Pasangan \& } \\
\text { Plesteran }\end{array}$ & & & & \\
\hline 1 & $\begin{array}{l}\text { Pasangan Batu Kosong } \\
\text { Aanstampeng } 15 / 20 \mathrm{~cm}\end{array}$ & $\begin{array}{r}11, \\
77\end{array}$ & $\begin{array}{c}\mathrm{M} \\
3 \\
\end{array}$ & $\begin{array}{r}433.878, \\
90 \\
\end{array}$ & $\begin{array}{r}5.106 .75 \\
4,65 \\
\end{array}$ \\
\hline 2 & Pasangan Batu Kali 1Pc:6Ps & $\begin{array}{r}43, \\
17 \\
\end{array}$ & $\begin{array}{c}\mathrm{M} \\
3 \\
\end{array}$ & $\begin{array}{r}766.469 \\
25 \\
\end{array}$ & $\begin{array}{r}33.088 .4 \\
77,52 \\
\end{array}$ \\
\hline 3 & $\begin{array}{l}\text { Pasang pondasi rollag bata } \\
\text { merah }\end{array}$ & $\begin{array}{r}7,2 \\
6 \\
\end{array}$ & $\begin{array}{c}\mathrm{M} \\
2\end{array}$ & $\begin{array}{r}263.465, \\
00 \\
\end{array}$ & $\begin{array}{r}1.912 .75 \\
5,90 \\
\end{array}$ \\
\hline 4 & $\begin{array}{l}\text { Pasangan bata merah tebal } 1 / 2 \\
\text { bata, } 1 \mathrm{Pc}: 2 \mathrm{Ps}\end{array}$ & $\begin{array}{r}15 \\
46 \\
\end{array}$ & $\begin{array}{l}\mathrm{M} \\
2 \\
\end{array}$ & $\begin{array}{r}127.535, \\
00 \\
\end{array}$ & $\begin{array}{r}1.971 .69 \\
1,10 \\
\end{array}$ \\
\hline 5 & $\begin{array}{l}\text { Pasangan bata merah tebal } 1 / 2 \\
\text { bata, } 1 \mathrm{Pc}: 4 \mathrm{Ps}\end{array}$ & $\begin{array}{r}22 \\
5,1 \\
8 \\
\end{array}$ & $\begin{array}{c}\mathrm{M} \\
2\end{array}$ & $\begin{array}{r}118.087 \\
75 \\
\end{array}$ & $\begin{array}{r}26.590 .9 \\
99,55 \\
\end{array}$ \\
\hline 6 & $\begin{array}{l}\text { Plesteran } 1 \mathrm{Pc}: 2 \mathrm{Ps} \text {, tebal } 15 \\
\mathrm{~mm}\end{array}$ & $\begin{array}{r}30 \\
92 \\
\end{array}$ & $\begin{array}{l}\mathrm{M} \\
2 \\
\end{array}$ & $\begin{array}{r}72.536,0 \\
2 \\
\end{array}$ & $\begin{array}{r}2.242 .81 \\
3,74 \\
\end{array}$ \\
\hline 7 & $\begin{array}{l}\text { Plesteran } 1 \mathrm{Pc}: 4 \mathrm{Ps} \text {, tebal } 15 \\
\mathrm{~mm}\end{array}$ & $\begin{array}{r}45 \\
0,3 \\
6 \\
\end{array}$ & $\begin{array}{c}\mathrm{M} \\
2\end{array}$ & $\begin{array}{r}61.085,7 \\
0\end{array}$ & $\begin{array}{r}27.510 .5 \\
55,85 \\
\end{array}$ \\
\hline
\end{tabular}




\begin{tabular}{|c|c|c|c|c|c|}
\hline 8 & Acian & $\begin{array}{r}48 \\
1,2 \\
8 \\
\end{array}$ & $\begin{array}{l}\mathrm{M} \\
2\end{array}$ & $\begin{array}{r}36.800,0 \\
0 \\
\end{array}$ & $\begin{array}{r}17.711 .1 \\
04,00 \\
\end{array}$ \\
\hline 9 & Pasang batu alam & $\begin{array}{r}8,9 \\
6\end{array}$ & $\begin{array}{c}\mathrm{M} \\
2\end{array}$ & $\begin{array}{r}310.787, \\
50\end{array}$ & $\begin{array}{r}2.784 .65 \\
6,00\end{array}$ \\
\hline $\begin{array}{l}1 \\
0\end{array}$ & Pasang Roster Beton & $\begin{array}{c}31, \\
00\end{array}$ & $\begin{array}{l}\text { B } \\
h\end{array}$ & $\begin{array}{r}18.884,3 \\
3 \\
\end{array}$ & $\begin{array}{r}585.414, \\
23 \\
\end{array}$ \\
\hline $\begin{array}{l}1 \\
1 \\
\end{array}$ & $\begin{array}{l}\text { Pelapisan Water Proofing Plat } \\
\text { Luifel }\end{array}$ & $\begin{array}{r}15, \\
52 \\
\end{array}$ & $\begin{array}{c}\mathrm{M} \\
2\end{array}$ & $\begin{array}{r}48.291,5 \\
0 \\
\end{array}$ & $\begin{array}{r}749.484, \\
08 \\
\end{array}$ \\
\hline \multicolumn{5}{|c|}{ Jumlah } & $\begin{array}{r}120.254 \\
706,62\end{array}$ \\
\hline D & PEKERJAAN BETON & & & & \\
\hline 1 & $\begin{array}{l}\text { RABAT BETON LANTAI } \\
\text { KERJA DAN CARPORT } \\
\end{array}$ & $\begin{array}{r}6,3 \\
2 \\
\end{array}$ & $\begin{array}{l}\mathrm{M} \\
3 \\
\end{array}$ & $\begin{array}{r}891.629, \\
50 \\
\end{array}$ & $\begin{array}{r}5.635 .09 \\
8,44\end{array}$ \\
\hline 2 & Beton Pondasi foot plat & & & & 0,00 \\
\hline & - Beton K-175 & $\begin{array}{r}1,0 \\
2\end{array}$ & $\begin{array}{l}\mathrm{M} \\
3 \\
\end{array}$ & $\begin{array}{r}891.629, \\
50 \\
\end{array}$ & $\begin{array}{r}909.462, \\
09 \\
\end{array}$ \\
\hline & - Pembesian & $\begin{array}{r}16 \\
1,8 \\
5\end{array}$ & $\begin{array}{l}K \\
\mathrm{~g}\end{array}$ & $\begin{array}{r}13.330,2 \\
3 \\
\end{array}$ & $\begin{array}{r}2.157 .49 \\
7,73 \\
\end{array}$ \\
\hline & - Bekisting & $\begin{array}{r}0,6 \\
4 \\
\end{array}$ & $\begin{array}{l}\mathrm{M} \\
2\end{array}$ & $\begin{array}{r}91.161,0 \\
8 \\
\end{array}$ & $\begin{array}{r}58.343,0 \\
9 \\
\end{array}$ \\
\hline \multirow[t]{4}{*}{3} & Beton Sloof $15 / 25$ & & & & \\
\hline & - Beton K-175 & $\begin{array}{r}2,9 \\
4\end{array}$ & $\begin{array}{c}\text { M } \\
3\end{array}$ & $\begin{array}{r}891.629, \\
50 \\
\end{array}$ & $\begin{array}{r}2.621 .39 \\
0,73 \\
\end{array}$ \\
\hline & - Pembesian & $\begin{array}{r}42 \\
3,0 \\
9 \\
\end{array}$ & $\begin{array}{l}\mathrm{K} \\
\mathrm{g}\end{array}$ & $\begin{array}{r}13.330,2 \\
3 \\
\end{array}$ & $\begin{array}{r}5.639 .88 \\
7,01 \\
\end{array}$ \\
\hline & - Bekisting & $\begin{array}{r}19, \\
62 \\
\end{array}$ & $\begin{array}{c}\mathrm{M} \\
2\end{array}$ & $\begin{array}{r}91.161,0 \\
8 \\
\end{array}$ & $\begin{array}{r}1.788 .58 \\
0,39 \\
\end{array}$ \\
\hline \multirow[t]{4}{*}{4} & Beton Kolom praktis $15 / 15$ & & & & \\
\hline & - Beton K-175 & $\begin{array}{r}2,3 \\
6 \\
\end{array}$ & $\begin{array}{l}\text { M } \\
3 \\
\end{array}$ & $\begin{array}{r}891.629, \\
50 \\
\end{array}$ & $\begin{array}{r}2.104 .24 \\
5,62 \\
\end{array}$ \\
\hline & - Pembesian & $\begin{array}{r}39 \\
6,9 \\
5 \\
\end{array}$ & $\begin{array}{l}K \\
\mathrm{~g}\end{array}$ & $\begin{array}{r}13.330,2 \\
3 \\
\end{array}$ & $\begin{array}{r}5.291 .43 \\
4,80 \\
\end{array}$ \\
\hline & - Bekisting & $\begin{array}{r}31, \\
50\end{array}$ & $\begin{array}{l}\mathrm{M} \\
2 \\
\end{array}$ & $\begin{array}{r}206.964, \\
35 \\
\end{array}$ & $\begin{array}{r}6.519 .37 \\
7,03 \\
\end{array}$ \\
\hline \multirow[t]{4}{*}{5} & Beton Kolom 15/20 & & & & \\
\hline & - Beton K-175 & $\begin{array}{r}0,4 \\
2 \\
\end{array}$ & $\begin{array}{l}\text { M } \\
3 \\
\end{array}$ & $\begin{array}{r}891.629, \\
50 \\
\end{array}$ & $\begin{array}{r}374.484, \\
39 \\
\end{array}$ \\
\hline & - Pembesian & $\begin{array}{r}56, \\
57\end{array}$ & $\begin{array}{c}\mathrm{K} \\
\mathrm{g}\end{array}$ & $\begin{array}{r}13.330,2 \\
3 \\
\end{array}$ & $\begin{array}{r}754.091, \\
11 \\
\end{array}$ \\
\hline & - Bekisting & $\begin{array}{r}4,9 \\
0\end{array}$ & $\begin{array}{c}\mathrm{M} \\
2\end{array}$ & $\begin{array}{r}206.964, \\
35 \\
\end{array}$ & $\begin{array}{r}1.014 .12 \\
5,32 \\
\end{array}$ \\
\hline \multirow[t]{4}{*}{6} & Beton Kolom 15/30 & & & & \\
\hline & - Beton K-175 & $\begin{array}{r}0,9 \\
4\end{array}$ & $\begin{array}{c}\mathrm{M} \\
3 \\
\end{array}$ & $\begin{array}{r}891.629, \\
50 \\
\end{array}$ & $\begin{array}{r}838.131, \\
73 \\
\end{array}$ \\
\hline & - Pembesian & $\begin{array}{r}11 \\
7,9 \\
5 \\
\end{array}$ & $\begin{array}{l}\mathrm{K} \\
\mathrm{g}\end{array}$ & $\begin{array}{r}13.330,2 \\
3 \\
\end{array}$ & $\begin{array}{r}1.572 .30 \\
0,63 \\
\end{array}$ \\
\hline & - Bekisting & $\begin{array}{r}9,4 \\
5 \\
\end{array}$ & $\begin{array}{l}\mathrm{M} \\
2\end{array}$ & $\begin{array}{r}206.964, \\
35 \\
\end{array}$ & $\begin{array}{r}1.955 .81 \\
3,11 \\
\end{array}$ \\
\hline \multirow[t]{4}{*}{7} & Beton Ringbalk & & & & \\
\hline & - Beton K-175 & $\begin{array}{r}2,7 \\
8\end{array}$ & $\begin{array}{c}\mathrm{M} \\
3\end{array}$ & $\begin{array}{r}891.629, \\
50 \\
\end{array}$ & $\begin{array}{r}2.478 .73 \\
0,01 \\
\end{array}$ \\
\hline & - Pembesian & $\begin{array}{r}46 \\
4,1 \\
2 \\
\end{array}$ & $\begin{array}{l}\mathrm{K} \\
\mathrm{g}\end{array}$ & $\begin{array}{r}13.330,2 \\
3 \\
\end{array}$ & $\begin{array}{r}6.186 .82 \\
6,35 \\
\end{array}$ \\
\hline & - Bekisting & $\begin{array}{r}18, \\
60\end{array}$ & $\begin{array}{c}\mathrm{M} \\
2\end{array}$ & $\begin{array}{r}206.964, \\
35 \\
\end{array}$ & $\begin{array}{r}3.849 .53 \\
6,91 \\
\end{array}$ \\
\hline \multirow[t]{4}{*}{8} & $\begin{array}{l}\text { Beton Balok dan Plat Atap } \\
\mathrm{t}=12 \mathrm{~cm}\end{array}$ & & & & \\
\hline & - Beton K-175 & $\begin{array}{r}1,5 \\
0\end{array}$ & $\begin{array}{c}\mathrm{M} \\
3 \\
\end{array}$ & $\begin{array}{r}891.629, \\
50 \\
\end{array}$ & $\begin{array}{r}1.337 .44 \\
4,25 \\
\end{array}$ \\
\hline & - Pembesian & $\begin{array}{r}33 \\
0,1 \\
8 \\
\end{array}$ & $\begin{array}{l}\mathrm{K} \\
\mathrm{g}\end{array}$ & $\begin{array}{r}13.330,2 \\
3 \\
\end{array}$ & $\begin{array}{r}4.401 .37 \\
5,34 \\
\end{array}$ \\
\hline & - Bekisting & $\begin{array}{r}14, \\
01\end{array}$ & $\begin{array}{c}\mathrm{M} \\
2\end{array}$ & $\begin{array}{r}206.964, \\
35 \\
\end{array}$ & $\begin{array}{r}2.899 .57 \\
0,54 \\
\end{array}$ \\
\hline \multicolumn{5}{|c|}{ Jumlah } & $\begin{array}{r}60.387 .7 \\
46,61 \\
\end{array}$ \\
\hline E & $\begin{array}{l}\text { PEKERJAAN PELAPIS } \\
\text { LANTAI DAN DINDING }\end{array}$ & & & & \\
\hline 1 & $\begin{array}{l}\text { Pasang Keramik Lantai Granite } \\
\text { Tile } 60 \text { X } 60\end{array}$ & $\begin{array}{r}99, \\
39 \\
\end{array}$ & $\begin{array}{l}\mathrm{M} \\
2 \\
\end{array}$ & $\begin{array}{r}315.399, \\
00 \\
\end{array}$ & $\begin{array}{r}31.347 .5 \\
06,61 \\
\end{array}$ \\
\hline 2 & $\begin{array}{l}\text { Pasang Keramik Dinding } \\
\text { KM/WC 20x25 }\end{array}$ & $\begin{array}{r}26, \\
1 \\
\end{array}$ & $\begin{array}{l}M \\
2\end{array}$ & $\begin{array}{r}216.931, \\
00 \\
\end{array}$ & $\begin{array}{r}5.661 .89 \\
9,10 \\
\end{array}$ \\
\hline 3 & $\begin{array}{l}\text { Pasang Keramik Lantai } \\
\text { KM/WC } 20 \times 20\end{array}$ & $\begin{array}{r}5,2 \\
5\end{array}$ & $\begin{array}{l}\mathrm{M} \\
2\end{array}$ & $\begin{array}{r}150.891, \\
50 \\
\end{array}$ & $\begin{array}{r}792.180, \\
38 \\
\end{array}$ \\
\hline
\end{tabular}

\begin{tabular}{|c|c|c|c|c|c|}
\hline 4 & Pasang List Keramik & $\begin{array}{r}17, \\
8\end{array}$ & $\begin{array}{l}\mathrm{M} \\
1 \\
\end{array}$ & $\begin{array}{r}51.282,0 \\
6 \\
\end{array}$ & $\begin{array}{r}912.820 \\
67 \\
\end{array}$ \\
\hline 5 & $\begin{array}{l}\text { Pasang Batu Ampyangan/koral } \\
\text { sikat }\end{array}$ & 30 & $\begin{array}{l}\mathrm{M} \\
2\end{array}$ & $\begin{array}{r}146.165, \\
00 \\
\end{array}$ & $\begin{array}{r}4.384 .95 \\
0,00 \\
\end{array}$ \\
\hline \multicolumn{5}{|c|}{ Jumlah } & $\begin{array}{r}43.099 .3 \\
56,75 \\
\end{array}$ \\
\hline $\mathbf{F}$ & $\begin{array}{l}\text { PEKERJAAN KUSEN, } \\
\text { PINTU, BESI, DAN KACA } \\
\end{array}$ & & & & \\
\hline 1 & $\begin{array}{l}\text { Pasang kusen pintu dan } \\
\text { jendela kayu Kamper }\end{array}$ & $\begin{array}{r}0,7 \\
0 \\
\end{array}$ & $\begin{array}{l}\mathrm{M} \\
3 \\
\end{array}$ & $\begin{array}{r}6.198 .62 \\
9,38 \\
\end{array}$ & $\begin{array}{r}4.339 .04 \\
0,57 \\
\end{array}$ \\
\hline 2 & $\begin{array}{l}\text { Pasang Daun Jendela Panil } \\
\text { Kaca }\end{array}$ & $\begin{array}{r}2,9 \\
8 \\
\end{array}$ & $\begin{array}{c}M \\
2\end{array}$ & $\begin{array}{r}519.042, \\
50 \\
\end{array}$ & $\begin{array}{r}1.546 .74 \\
6,65 \\
\end{array}$ \\
\hline 3 & $\begin{array}{l}\text { Pasang Daun Pintu Panil Kayu } \\
80 \times 220 \mathrm{~cm}\end{array}$ & $\begin{array}{r}14, \\
80 \\
\end{array}$ & $\begin{array}{c}M \\
2 \\
\end{array}$ & $\begin{array}{r}519.042, \\
50 \\
\end{array}$ & $\begin{array}{r}7.681 .82 \\
9,00 \\
\end{array}$ \\
\hline 4 & $\begin{array}{l}\text { Pasang Kusen \& Daun Pintu } \\
\text { PVC }\end{array}$ & 3 & $\begin{array}{l}\mathrm{B} \\
\mathrm{h}\end{array}$ & $\begin{array}{r}325.000, \\
00 \\
\end{array}$ & $\begin{array}{r}975.000, \\
00\end{array}$ \\
\hline 5 & Pasang Kaca Polos $5 \mathrm{~mm}$ & $\begin{array}{r}5,1 \\
1 \\
\end{array}$ & $\begin{array}{c}\mathrm{M} \\
2 \\
\end{array}$ & $\begin{array}{r}178.379 \\
95 \\
\end{array}$ & $\begin{array}{r}911.521, \\
54 \\
\end{array}$ \\
\hline 6 & $\begin{array}{l}\text { Pasang Kunci Pintu Tanam } \\
\text { dan Handle }\end{array}$ & 9 & $\begin{array}{l}\mathrm{B} \\
\mathrm{h}\end{array}$ & $\begin{array}{r}362.744, \\
50 \\
\end{array}$ & $\begin{array}{r}3.264 .70 \\
0,50 \\
\end{array}$ \\
\hline 7 & Pasang Engsel Pintu 4" & 27 & $\begin{array}{l}\mathrm{B} \\
\mathrm{h}\end{array}$ & $\begin{array}{r}47.567,4 \\
5 \\
\end{array}$ & $\begin{array}{r}1.284 .32 \\
1,15 \\
\end{array}$ \\
\hline 8 & Pasang Engsel Jendela & 20 & $\begin{array}{l}\mathrm{B} \\
\mathrm{h}\end{array}$ & $\begin{array}{r}41.290,7 \\
5 \\
\end{array}$ & $\begin{array}{r}825.815, \\
00\end{array}$ \\
\hline 9 & Pasang Grendel Jendela & 10 & $\begin{array}{l}\text { B } \\
\mathrm{h}\end{array}$ & $\begin{array}{r}38.415,7 \\
5 \\
\end{array}$ & $\begin{array}{r}384.157, \\
50 \\
\end{array}$ \\
\hline \multicolumn{5}{|c|}{ Jumlah } & $\begin{array}{r}21.213 .1 \\
31,91 \\
\end{array}$ \\
\hline G & $\begin{array}{l}\text { PEKERJAAN KAP ATAP } \\
\text { DAN PLATFOND }\end{array}$ & & & & \\
\hline 1 & Pek. Kuda-kuda Baja Ringan & $\begin{array}{r}15 \\
5,8 \\
1 \\
\end{array}$ & $\begin{array}{c}\mathrm{M} \\
2 \\
\end{array}$ & $\begin{array}{r}180.000 \\
00 \\
\end{array}$ & $\begin{array}{r}28.045 .8 \\
00,00 \\
\end{array}$ \\
\hline & - Truss C- $75,0.75$ & & & & \\
\hline & - Reng R.33-0.45 & & & & \\
\hline 2 & $\begin{array}{l}\text { Pasang Penutup Atap Genteng } \\
\text { Metal }\end{array}$ & $\begin{array}{r}15 \\
5,8 \\
1 \\
\end{array}$ & $\begin{array}{c}\mathrm{M} \\
2 \\
\end{array}$ & $\begin{array}{r}84.396,2 \\
0 \\
\end{array}$ & $\begin{array}{r}13.149 .7 \\
71,92 \\
\end{array}$ \\
\hline 3 & $\begin{array}{l}\text { Pasang Bubungan Atap } \\
\text { Genteng Metal }\end{array}$ & $\begin{array}{r}51, \\
62 \\
\end{array}$ & $\begin{array}{c}\mathrm{M} \\
1 \\
\end{array}$ & $\begin{array}{r}71.159,2 \\
8 \\
\end{array}$ & $\begin{array}{r}3.673 .24 \\
2,03 \\
\end{array}$ \\
\hline 4 & $\begin{array}{l}\text { Pasang penutup plafond } \\
\text { gypsumboard dan rangka } \\
\text { hollow galv. }\end{array}$ & $\begin{array}{r}82, \\
50\end{array}$ & $\begin{array}{c}\mathrm{M} \\
2\end{array}$ & $\begin{array}{r}80.787,5 \\
0 \\
\end{array}$ & $\begin{array}{r}6.664 .96 \\
8,75 \\
\end{array}$ \\
\hline 5 & $\begin{array}{l}\text { Pasang Penutup plafond } \\
\text { kalsiboard overstek, km/wc } \\
\text { dan rangka }\end{array}$ & $\begin{array}{r}44, \\
25\end{array}$ & $\begin{array}{c}\mathrm{M} \\
2 \\
\end{array}$ & $\begin{array}{r}80.787,5 \\
0 \\
\end{array}$ & $\begin{array}{r}3.574 .84 \\
6,88 \\
\end{array}$ \\
\hline 6 & Pasang jurai talang galvalum & $\begin{array}{r}13, \\
34 \\
\end{array}$ & $\begin{array}{c}\mathrm{M} \\
1 \\
\end{array}$ & $\begin{array}{r}228.545, \\
65 \\
\end{array}$ & $\begin{array}{r}3.048 .79 \\
8,97 \\
\end{array}$ \\
\hline 7 & $\begin{array}{l}\text { List plank kalsiplank } \\
2 \times 1 / 10 ; 1 / 20\end{array}$ & $\begin{array}{r}49, \\
25 \\
\end{array}$ & $\begin{array}{c}\mathrm{M} \\
1 \\
\end{array}$ & $\begin{array}{r}105.223 \\
17 \\
\end{array}$ & $\begin{array}{r}5.182 .24 \\
1,12 \\
\end{array}$ \\
\hline 8 & Pasang Lis Gypsum & $\begin{array}{r}10 \\
4,0 \\
0 \\
\end{array}$ & $\begin{array}{c}\mathrm{M} \\
1\end{array}$ & $\begin{array}{r}15.272,0 \\
0 \\
\end{array}$ & $\begin{array}{r}1.588 .28 \\
8,00 \\
\end{array}$ \\
\hline \multicolumn{5}{|c|}{ Jumlah } & $\begin{array}{r}64.927 .9 \\
57,67 \\
\end{array}$ \\
\hline H & $\begin{array}{l}\text { PEKERJAAN } \\
\text { PENGECATAN }\end{array}$ & & & & \\
\hline 1 & Pengecatan Plafound & $\begin{array}{r}11 \\
8,3 \\
2 \\
\end{array}$ & $\begin{array}{c}\mathrm{M} \\
2 \\
\end{array}$ & $\begin{array}{r}22.051,2 \\
5 \\
\end{array}$ & $\begin{array}{r}2.609 .10 \\
3,90 \\
\end{array}$ \\
\hline 2 & Pengecatan Kayu & $\begin{array}{r}27, \\
21\end{array}$ & $\begin{array}{c}M \\
2\end{array}$ & $\begin{array}{r}47.265,0 \\
0 \\
\end{array}$ & $\begin{array}{r}1.286 .08 \\
0,65 \\
\end{array}$ \\
\hline 3 & Pengecatan Dinding Luar & $\begin{array}{r}16 \\
2,1 \\
8 \\
\end{array}$ & $\begin{array}{l}\mathrm{M} \\
2 \\
\end{array}$ & $\begin{array}{r}41.187,2 \\
5 \\
\end{array}$ & $\begin{array}{r}6.679 .74 \\
8,21 \\
\end{array}$ \\
\hline 4 & Pengecatan Dinding Dalam & $\begin{array}{r}37 \\
6,2 \\
8 \\
\end{array}$ & $\begin{array}{l}M \\
2 \\
\end{array}$ & $\begin{array}{r}22.051,2 \\
5 \\
\end{array}$ & $\begin{array}{r}8.297 .44 \\
4,35 \\
\end{array}$ \\
\hline 5 & Pengecatan Daun Pintu & $\begin{array}{r}29, \\
61 \\
\end{array}$ & $\begin{array}{c}\mathrm{M} \\
2 \\
\end{array}$ & $\begin{array}{r}47.265,0 \\
0 \\
\end{array}$ & $\begin{array}{r}1.399 .51 \\
6,65 \\
\end{array}$ \\
\hline 6 & Coating Batu Alam & $\begin{array}{r}8,9 \\
6 \\
\end{array}$ & $\begin{array}{c}\mathrm{M} \\
2\end{array}$ & $\begin{array}{r}47.345,5 \\
0 \\
\end{array}$ & $\begin{array}{r}424.215, \\
68 \\
\end{array}$ \\
\hline \multicolumn{5}{|c|}{ Jumlah } & $\begin{array}{r}20.696 .1 \\
09,44 \\
\end{array}$ \\
\hline I & $\begin{array}{l}\text { PEKERJAAN } \\
\text { ELEKTRIKAL } \\
\end{array}$ & & & & \\
\hline 1 & $\begin{array}{l}\text { Lampu Down Light } 5 \text { " TYPE } \\
\text { SK-501-2K-ADJ Tornado } 20 \\
\text { WATT }\end{array}$ & 7 & $\begin{array}{l}\mathrm{B} \\
\mathrm{h}\end{array}$ & $\begin{array}{r}319.182, \\
50 \\
\end{array}$ & $\begin{array}{r}2.234 .27 \\
7,50 \\
\end{array}$ \\
\hline 2 & $\begin{array}{l}\text { Lampu Down Light 5" TYPE } \\
\text { SK-501-2K-ADJ Tornado } 15 \\
\text { WATT }\end{array}$ & 11 & $\begin{array}{l}\text { B } \\
\mathrm{h}\end{array}$ & $\begin{array}{r}366.045, \\
00 \\
\end{array}$ & $\begin{array}{r}4.026 .49 \\
5,00 \\
\end{array}$ \\
\hline 3 & $\begin{array}{l}\text { Pasang Titik Instalasi Stop } \\
\text { Kontak Dinding }\end{array}$ & 9 & $\begin{array}{l}\mathrm{Ti} \\
\mathrm{ti} \\
\mathrm{k}\end{array}$ & $\begin{array}{r}223.617 \\
50 \\
\end{array}$ & $\begin{array}{r}2.012 .55 \\
7,50 \\
\end{array}$ \\
\hline
\end{tabular}




\begin{tabular}{|c|c|c|c|c|c|}
\hline 4 & $\begin{array}{l}\text { Pas.Titik Inst. Penerangan } \\
\text { (NYM } 2 \times 2,5 \mathrm{~mm} 2)\end{array}$ & 18 & $\begin{array}{l}\mathrm{Ti} \\
\mathrm{ti} \\
\mathrm{k}\end{array}$ & $\begin{array}{r}192.567, \\
50 \\
\end{array}$ & $\begin{array}{r}3.466 .21 \\
5,00 \\
\end{array}$ \\
\hline 5 & Pasang Saklar Tunggal & 9 & $\begin{array}{l}\mathrm{B} \\
\mathrm{h}\end{array}$ & $\begin{array}{r}15.400,0 \\
0 \\
\end{array}$ & $\begin{array}{r}138.600, \\
00 \\
\end{array}$ \\
\hline 6 & Pasang Saklar Ganda & 5 & $\begin{array}{l}\mathrm{B} \\
\mathrm{h}\end{array}$ & $\begin{array}{r}19.800,0 \\
0\end{array}$ & $\begin{array}{r}99.000,0 \\
0 \\
\end{array}$ \\
\hline 7 & Pasang Stop Kontak & 9 & $\begin{array}{l}\mathrm{B} \\
\mathrm{h}\end{array}$ & $\begin{array}{r}21.000,0 \\
0 \\
\end{array}$ & $\begin{array}{r}189.000, \\
00 \\
\end{array}$ \\
\hline 8 & Pasang Panel & 1 & $\begin{array}{c}\mathrm{U} \\
\mathrm{ni} \\
\mathrm{t}\end{array}$ & $\begin{array}{r}465.000, \\
00 \\
\end{array}$ & $\begin{array}{r}465.000, \\
00\end{array}$ \\
\hline & Jumlah & & & & $\begin{array}{r}12.631 .1 \\
45,00 \\
\end{array}$ \\
\hline $\mathbf{J}$ & PEKERJAAN SANITAIR & & & & \\
\hline 1 & $\begin{array}{l}\text { Pasang Klosed Duduk } \\
\text { Lengkap dengan Tabung } \\
\text { Gelontor }\end{array}$ & 2 & $\begin{array}{l}\text { B } \\
\mathrm{h}\end{array}$ & $\begin{array}{r}3.200 .56 \\
5,00 \\
\end{array}$ & $\begin{array}{r}6.401 .13 \\
0,00 \\
\end{array}$ \\
\hline 2 & Pasang Kloset Jongkok & 1 & $\begin{array}{l}\text { B } \\
\mathrm{h}\end{array}$ & $\begin{array}{r}667.517, \\
50 \\
\end{array}$ & $\begin{array}{r}667.517, \\
50 \\
\end{array}$ \\
\hline 3 & Pasang Toilet Sprayer & 1 & $\begin{array}{l}\text { B } \\
\mathrm{h}\end{array}$ & $\begin{array}{r}329.631, \\
69 \\
\end{array}$ & $\begin{array}{r}329.631, \\
69 \\
\end{array}$ \\
\hline 4 & Pasang Afoor/Flour drain & 4 & $\begin{array}{l}\mathrm{B} \\
\mathrm{h}\end{array}$ & $\begin{array}{r}144.210, \\
00\end{array}$ & $\begin{array}{r}576.840, \\
00\end{array}$ \\
\hline 5 & Pasang Kran 1/2" & 7 & $\begin{array}{l}\mathrm{B} \\
\mathrm{h}\end{array}$ & $\begin{array}{r}21.361,2 \\
5 \\
\end{array}$ & $\begin{array}{r}149.528, \\
75 \\
\end{array}$ \\
\hline 6 & $\begin{array}{l}\text { Pasang Kitchen Zink / Bak } \\
\text { Cuci }\end{array}$ & 1 & $\begin{array}{l}\mathrm{B} \\
\mathrm{h}\end{array}$ & $\begin{array}{r}276.905, \\
63 \\
\end{array}$ & $\begin{array}{r}276.905, \\
63 \\
\end{array}$ \\
\hline 7 & Pasang Kran Kitchen Zink & 1 & $\begin{array}{l}\mathrm{B} \\
\mathrm{h}\end{array}$ & $\begin{array}{r}300.881, \\
69 \\
\end{array}$ & $\begin{array}{r}300.881, \\
69 \\
\end{array}$ \\
\hline 8 & Pasang Pipa PVC dia 1/2" & $\begin{array}{r}37, \\
38 \\
\end{array}$ & $\begin{array}{c}\mathrm{M} \\
1 \\
\end{array}$ & $\begin{array}{r}23.149,5 \\
0 \\
\end{array}$ & $\begin{array}{r}865.328, \\
31 \\
\end{array}$ \\
\hline 9 & Pasang Pipa PVC tipe D dia 2" & $\begin{array}{r}6,0 \\
5\end{array}$ & $\begin{array}{c}\mathrm{M} \\
1 \\
\end{array}$ & $\begin{array}{r}42.745,5 \\
0 \\
\end{array}$ & $\begin{array}{r}258.610, \\
28 \\
\end{array}$ \\
\hline $\begin{array}{l}1 \\
0 \\
\end{array}$ & Pasang Pipa PVC tipe D dia 3" & $\begin{array}{r}32, \\
81 \\
\end{array}$ & $\begin{array}{c}\mathrm{M} \\
1 \\
\end{array}$ & $\begin{array}{r}76.184,6 \\
3 \\
\end{array}$ & $\begin{array}{r}2.499 .61 \\
7,71 \\
\end{array}$ \\
\hline $\begin{array}{l}1 \\
1\end{array}$ & Pasang Pipa PVC tipe D dia 4" & $\begin{array}{r}25, \\
05\end{array}$ & $\begin{array}{c}\mathrm{M} \\
1\end{array}$ & $\begin{array}{r}99.705,0 \\
0\end{array}$ & $\begin{array}{r}2.497 .61 \\
0,25\end{array}$ \\
\hline $\begin{array}{l}1 \\
2\end{array}$ & $\begin{array}{l}\text { Pasang Septictank Biofilter } \\
\text { kap. } 1,5 \mathrm{~m}^{3}\end{array}$ & 1 & $\begin{array}{c}\mathrm{U} \\
\mathrm{ni} \\
\mathrm{t}\end{array}$ & $\begin{array}{r}5.536 .00 \\
0,00 \\
\end{array}$ & $\begin{array}{r}5.536 .00 \\
0,00 \\
\end{array}$ \\
\hline \multicolumn{5}{|c|}{ Jumlah } & $\begin{array}{r}20.359 .6 \\
01,81 \\
\end{array}$ \\
\hline \multicolumn{5}{|c|}{ TOTAL KESELURUHAN PEKERJAAN (Rp.) } & $\begin{array}{r}394.578 . \\
605,85 \\
\end{array}$ \\
\hline \multicolumn{5}{|c|}{ PPN (10\%) } & $\begin{array}{r}39.457 .8 \\
60,59 \\
\end{array}$ \\
\hline \multicolumn{5}{|c|}{$\begin{array}{l}\text { TOTAL KESELURUHAN PEKERJAAN (Rp.) + Jumlah } \\
\text { PPN (10\%) (Rp.) }\end{array}$} & $\begin{array}{r}434.036 . \\
466,44 \\
\end{array}$ \\
\hline
\end{tabular}

\subsection{Daftar Rencana Anggaran \\ Biaya Menurut Kontraktor}

Tabel 2 : Rencana Anggaran Biaya Menurut Kontraktor

\begin{tabular}{|c|c|c|c|c|c|}
\hline $\begin{array}{l}\mathbf{N} \\
\mathbf{0}\end{array}$ & Item Pekerjaan & Volume & Sat & $\begin{array}{c}\text { Harg } \\
\text { a } \\
\text { Satua } \\
\mathbf{n} \\
\text { (Rp) }\end{array}$ & $\begin{array}{c}\text { Jumla } \\
\text { h } \\
\text { Harga } \\
\text { (Rp) }\end{array}$ \\
\hline A & Pekerjaan Persiapan & & & & \\
\hline 1 & Pembersihan Halaman & 288,00 & M2 & $\begin{array}{r}7.700, \\
00 \\
\end{array}$ & $\begin{array}{r}2.217 . \\
600,00 \\
\end{array}$ \\
\hline 2 & $\begin{array}{l}\text { Pengukuran dan } \\
\text { Pemasangan Bowplank }\end{array}$ & 51,00 & $\mathrm{M}^{\prime}$ & $\begin{array}{r}60.47 \\
0,74 \\
\end{array}$ & $\begin{array}{r}3.084 \\
007,74\end{array}$ \\
\hline \multicolumn{5}{|c|}{ Jumlah } & $\begin{array}{r}5.301 . \\
607,74 \\
\end{array}$ \\
\hline B & Pekerjaan Tanah & & & & \\
\hline 1 & $\begin{array}{l}\text { Galian Tanah } \\
\text { Pondasi Batu Kali }\end{array}$ & 94,20 & M3 & $\begin{array}{r}73.15 \\
0,00 \\
\end{array}$ & $\begin{array}{r}6.890 . \\
730,00 \\
\end{array}$ \\
\hline 2 & Urugan kembali & 23,64 & M3 & $\begin{array}{r}24.34 \\
3,00 \\
\end{array}$ & $\begin{array}{r}575.46 \\
8,52 \\
\end{array}$ \\
\hline 3 & $\begin{array}{l}\text { Urugan Tanah untuk } \\
\text { Peninggian Muka } \\
\text { Lantai }\end{array}$ & 18,84 & M3 & $\begin{array}{l}167.8 \\
60,00 \\
\end{array}$ & $\begin{array}{r}3.162 . \\
482,40 \\
\end{array}$ \\
\hline 4 & $\begin{array}{l}\text { Urugan Pasir Bawah } \\
\text { Pondasi Batu Kali, t } \\
=10 \mathrm{~cm}\end{array}$ & 7,85 & M3 & $\begin{array}{l}132.2 \\
20,00 \\
\end{array}$ & $\begin{array}{r}1.037 . \\
927,00 \\
\end{array}$ \\
\hline 5 & $\begin{array}{l}\text { Urugan Pasir Bawah } \\
\text { Lantai } t=5 \mathrm{~cm}\end{array}$ & 3,92 & M3 & $\begin{array}{l}132.2 \\
20,00\end{array}$ & $\begin{array}{r}518.30 \\
2,40 \\
\end{array}$ \\
\hline
\end{tabular}

\begin{tabular}{|c|c|c|c|c|c|}
\hline \multicolumn{5}{|c|}{ Jumlah } & \multirow[t]{2}{*}{$\begin{array}{r}12.184 \\
.910,3 \\
2\end{array}$} \\
\hline C & $\begin{array}{l}\text { Pekerjaan Pasangan \& } \\
\text { Plesteran }\end{array}$ & & & & \\
\hline 1 & $\begin{array}{l}\text { Pasangan Batu Kosong } \\
\text { Aanstampeng } 15 / 20 \mathrm{~cm}\end{array}$ & 11,77 & M3 & $\begin{array}{l}415.0 \\
14,60\end{array}$ & $\begin{array}{r}4.884 \\
721,84\end{array}$ \\
\hline 2 & $\begin{array}{l}\text { Pasangan Batu Kali 1Pc: } \\
\text { 6Ps }\end{array}$ & 43,17 & M3 & $\begin{array}{l}733.1 \\
44,50\end{array}$ & $\begin{array}{r}31.649 \\
.848,0 \\
7\end{array}$ \\
\hline 3 & $\begin{array}{l}\text { Pasang pondasi rollag } \\
\text { bata merah }\end{array}$ & 7,26 & M2 & $\begin{array}{l}252.0 \\
10,00 \\
\end{array}$ & $\begin{array}{r}1.829 . \\
592,60\end{array}$ \\
\hline 4 & $\begin{array}{l}\text { Pasangan bata merah } \\
\text { tebal } 1 / 2 \text { bata, } 1 \mathrm{Pc}: 2 \mathrm{Ps}\end{array}$ & 15,46 & M2 & $\begin{array}{l}121.9 \\
90,00\end{array}$ & $\begin{array}{r}1.885 \\
965,40\end{array}$ \\
\hline 5 & $\begin{array}{l}\text { Pasangan bata merah } \\
\text { tebal } 1 / 2 \text { bata, } 1 \mathrm{Pc}: 4 \mathrm{Ps}\end{array}$ & 225,18 & M2 & $\begin{array}{l}112.9 \\
53,50\end{array}$ & $\begin{array}{r}25.434 \\
.869,1 \\
3\end{array}$ \\
\hline 6 & $\begin{array}{l}\text { Plesteran } 1 \mathrm{Pc}: 2 \mathrm{Ps} \text {, } \\
\text { tebal } 15 \mathrm{~mm}\end{array}$ & 30,92 & M2 & $\begin{array}{r}63.05 \\
0,68\end{array}$ & $\begin{array}{r}1.949 \\
527,03\end{array}$ \\
\hline 7 & $\begin{array}{l}\text { Plesteran } 1 \mathrm{Pc}: 4 \mathrm{Ps} \text {, } \\
\text { tebal } 15 \mathrm{~mm}\end{array}$ & 450,36 & M2 & $\begin{array}{r}58.42 \\
9,80\end{array}$ & $\begin{array}{r}26.314 \\
.444,7 \\
3\end{array}$ \\
\hline 8 & Acian & 481,28 & M2 & $\begin{array}{r}35.20 \\
0,00\end{array}$ & $\begin{array}{r}16.941 \\
.056,0 \\
0\end{array}$ \\
\hline 9 & Pasang batu alam & 8,96 & M2 & $\begin{array}{l}297.2 \\
75,00\end{array}$ & $\begin{array}{r}2.663 \\
584,00\end{array}$ \\
\hline 10 & Pasang Roster Beton & 31,00 & $\mathrm{Bh}$ & $\begin{array}{r}18.06 \\
3,27\end{array}$ & $\begin{array}{r}559.96 \\
1,32\end{array}$ \\
\hline 11 & $\begin{array}{l}\text { Pelapisan Water Proofing } \\
\text { Plat Luifel }\end{array}$ & 15,52 & M2 & $\begin{array}{r}46.12 \\
3,00\end{array}$ & $\begin{array}{r}715.82 \\
8,96\end{array}$ \\
\hline & Jum & & & & $\begin{array}{r}114.82 \\
9.399 \\
07\end{array}$ \\
\hline D & Pekerjaan Beton & & & & \\
\hline 1 & $\begin{array}{l}\text { Rabat Beton Lantai } \\
\text { Kerja dan Carport }\end{array}$ & 6,32 & M3 & $\begin{array}{l}874.0 \\
44,11 \\
\end{array}$ & $\begin{array}{r}5.523 \\
958,78 \\
\end{array}$ \\
\hline 2 & Beton Pondasi foot plat & & & & - \\
\hline & - Beton K-175 & 1,02 & M3 & $\begin{array}{l}874.0 \\
44,11\end{array}$ & $\begin{array}{r}891.52 \\
4,99\end{array}$ \\
\hline & - Pembesian & 161,85 & $\mathrm{Kg}$ & $\begin{array}{r}12.75 \\
0,65\end{array}$ & $\begin{array}{r}2.063 \\
692,70 \\
\end{array}$ \\
\hline & - Bekisting & 0,64 & M2 & $\begin{array}{r}87.19 \\
7.55\end{array}$ & $\begin{array}{r}55.806 \\
.43\end{array}$ \\
\hline 3 & Beton Sloof $15 / 25$ & & & & \\
\hline & - Beton K-175 & 2,94 & M3 & $\begin{array}{l}874.0 \\
44,11\end{array}$ & $\begin{array}{r}2.569 \\
689,69\end{array}$ \\
\hline & - Pembesian & 423,09 & $\mathrm{Kg}$ & $\begin{array}{r}12.75 \\
0,65 \\
\end{array}$ & $\begin{array}{r}5.394 \\
672,51 \\
\end{array}$ \\
\hline & - Bekisting & 19,62 & M2 & $\begin{array}{r}87.19 \\
7,55\end{array}$ & $\begin{array}{r}1.710 . \\
815,93\end{array}$ \\
\hline 4 & $\begin{array}{l}\text { Beton Kolom praktis } \\
15 / 15\end{array}$ & & & & \\
\hline & - Beton K-175 & 2,36 & M3 & $\begin{array}{l}874.0 \\
44,11\end{array}$ & $\begin{array}{r}2.062 \\
744,10\end{array}$ \\
\hline & - Pembesian & 396,95 & $\mathrm{Kg}$ & $\begin{array}{r}12.75 \\
0,65\end{array}$ & $\begin{array}{r}5.061 \\
370,52\end{array}$ \\
\hline & - Bekisting & 31,5 & M2 & $\begin{array}{l}170.0 \\
14,24\end{array}$ & $\begin{array}{r}5.355 \\
448,56 \\
\end{array}$ \\
\hline 5 & Beton Kolom 15/20 & & & & \\
\hline & - Beton K-175 & 0,42 & M3 & $\begin{array}{l}874.0 \\
44,11\end{array}$ & $\begin{array}{r}367.09 \\
8,53\end{array}$ \\
\hline & - Pembesian & 56,57 & $\mathrm{Kg}$ & $\begin{array}{r}12.75 \\
0,65\end{array}$ & $\begin{array}{r}721.30 \\
4,27\end{array}$ \\
\hline & - Bekisting & 4,9 & M2 & $\begin{array}{l}170.0 \\
14,24 \\
\end{array}$ & $\begin{array}{r}833.06 \\
9,78 \\
\end{array}$ \\
\hline 6 & Beton Kolom 15/30 & & & & \\
\hline & - Beton K-175 & 0,94 & M3 & $\begin{array}{l}874.0 \\
44,11\end{array}$ & $\begin{array}{r}821.60 \\
1,46\end{array}$ \\
\hline
\end{tabular}




\section{https://doi.org/10.47233/jteksis.v3i1.222}

\begin{tabular}{|c|c|c|c|c|c|}
\hline & - Pembesian & 117,95 & $\mathrm{Kg}$ & $\begin{array}{r}12.75 \\
0,65 \\
\end{array}$ & $\begin{array}{r}1.503 . \\
939,17\end{array}$ \\
\hline & - Bekisting & 9,45 & M2 & $\begin{array}{l}170.0 \\
14,24\end{array}$ & $\begin{array}{r}1.606 . \\
634,57\end{array}$ \\
\hline \multirow[t]{4}{*}{7} & Beton Ringbalk & & & & \\
\hline & - Beton K-175 & 2,78 & M3 & $\begin{array}{l}874.0 \\
44,11\end{array}$ & $\begin{array}{r}2.429 . \\
842,63 \\
\end{array}$ \\
\hline & - Pembesian & 464,12 & $\mathrm{Kg}$ & $\begin{array}{r}12.75 \\
0,65\end{array}$ & $\begin{array}{r}5.917 . \\
831,68\end{array}$ \\
\hline & - Bekisting & 18,6 & M2 & $\begin{array}{l}170.0 \\
14.24\end{array}$ & $\begin{array}{r}3.162 . \\
264.86\end{array}$ \\
\hline \multirow[t]{4}{*}{8} & $\begin{array}{l}\text { Beton Balok dan Plat } \\
\text { Atap } \mathrm{t}=12 \mathrm{~cm}\end{array}$ & & & & \\
\hline & - Beton K-175 & 1,5 & M3 & $\begin{array}{l}874.0 \\
44,11\end{array}$ & $\begin{array}{r}1.311 \\
066,17\end{array}$ \\
\hline & - Pembesian & 330,18 & $\mathrm{Kg}$ & $\begin{array}{r}12.75 \\
0,65\end{array}$ & $\begin{array}{r}4.210 . \\
009,62\end{array}$ \\
\hline & - Bekisting & 14,01 & M2 & $\begin{array}{l}170.0 \\
14,24\end{array}$ & $\begin{array}{r}2.381 \text {. } \\
899,50\end{array}$ \\
\hline \multicolumn{5}{|c|}{ Jumlah } & $\begin{array}{r}55.956 \\
.286,4 \\
4\end{array}$ \\
\hline $\mathbf{E}$ & $\begin{array}{l}\text { Pekerjaan Pelapis } \\
\text { Lantai dan Dinding }\end{array}$ & & & & \\
\hline 1 & $\begin{array}{l}\text { Pasang Keramik Lantai } \\
\text { Granite Tile } 60 \text { X } 60\end{array}$ & 99,39 & M2 & $\begin{array}{l}287.529, \\
00\end{array}$ & $\begin{array}{r}28.577 \\
.507,3 \\
1\end{array}$ \\
\hline 2 & $\begin{array}{l}\text { Pasang Keramik Dinding } \\
\text { KM/WC 20x25 }\end{array}$ & 26,1 & M2 & $\begin{array}{l}207.482, \\
00\end{array}$ & $\begin{array}{r}5.415 . \\
280,20\end{array}$ \\
\hline 3 & $\begin{array}{l}\text { Pasang Keramik Lantai } \\
\text { KM/WC 20x20 }\end{array}$ & 5,25 & M2 & $\begin{array}{l}205.953, \\
00\end{array}$ & $\begin{array}{r}1.081 . \\
253,25\end{array}$ \\
\hline 4 & Pasang List Keramik & 17,8 & M1 & $\begin{array}{l}46.193,1 \\
3\end{array}$ & $\begin{array}{r}822.23 \\
7,63\end{array}$ \\
\hline 5 & $\begin{array}{l}\text { Pasang Batu } \\
\text { Ampyangan/koral sikat }\end{array}$ & 30 & M2 & $\begin{array}{l}161.901, \\
30\end{array}$ & $\begin{array}{r}4.857 \\
039,00\end{array}$ \\
\hline \multicolumn{5}{|c|}{ Jumlah } & $\begin{array}{r}40.753 \\
.317,3 \\
9\end{array}$ \\
\hline $\mathbf{F}$ & $\begin{array}{l}\text { Pekerjaan Kusen, } \\
\text { Pintu, Besi, dan Kaca }\end{array}$ & & & & \\
\hline 1 & $\begin{array}{l}\text { Pasang kusen pintu dan } \\
\text { jendela kayu Kamper }\end{array}$ & 0,7 & M3 & $.929 .123,75$ & $\begin{array}{r}4.150 . \\
386,63 \\
\end{array}$ \\
\hline 2 & $\begin{array}{l}\text { Pasang Daun Jendela } \\
\text { Panil Kaca }\end{array}$ & $\begin{array}{r}2,9 \\
8\end{array}$ & M2 & $565.345,00$ & $\begin{array}{r}1.684 \\
728,10\end{array}$ \\
\hline 3 & $\begin{array}{l}\text { Pasang Daun Pintu Panil } \\
\text { Kayu } 80 \times 220 \mathrm{~cm}\end{array}$ & $\begin{array}{r}14, \\
8\end{array}$ & M2 & $565.345,00$ & $\begin{array}{r}8.367 \\
106,00\end{array}$ \\
\hline 4 & $\begin{array}{l}\text { Pasang Kusen \& Daun } \\
\text { Pintu PVC }\end{array}$ & 3 & $\mathrm{Bh}$ & $325.000,00$ & $\begin{array}{r}975.00 \\
0,00\end{array}$ \\
\hline 5 & Pasang Kaca Polos $5 \mathrm{~mm}$ & $\begin{array}{r}5,1 \\
1\end{array}$ & M2 & $170.624,30$ & $\begin{array}{r}871.89 \\
0,17\end{array}$ \\
\hline 6 & $\begin{array}{l}\text { Pasang Kunci Pintu } \\
\text { Tanam dan Handle }\end{array}$ & 9 & $\mathrm{Bh}$ & $346.973,00$ & $\begin{array}{r}3.122 . \\
757,00 \\
\end{array}$ \\
\hline 7 & Pasang Engsel Pintu 4" & 27 & $\mathrm{Bh}$ & $45.493,25$ & $\begin{array}{r}1.228 . \\
317,75 \\
\end{array}$ \\
\hline 8 & Pasang Engsel Jendela & 20 & $\mathrm{Bh}$ & $33.995,50$ & $\begin{array}{r}679.91 \\
0,00\end{array}$ \\
\hline 9 & Pasang Grendel Jendela & 10 & $\mathrm{Bh}$ & $36.745,50$ & $\begin{array}{r}367.45 \\
5,00 \\
\end{array}$ \\
\hline \multicolumn{5}{|c|}{ Jumlah } & $\begin{array}{r}21.447 \\
.550,6 \\
5\end{array}$ \\
\hline G & $\begin{array}{l}\text { Pekerjaan Kap Atap } \\
\text { dan Platfond }\end{array}$ & & & & \\
\hline 1 & $\begin{array}{l}\text { Pek. Kuda-kuda Baja } \\
\text { Ringan }\end{array}$ & 155,81 & M2 & $\begin{array}{l}180.0 \\
00,00 \\
\end{array}$ & $\begin{array}{r}28.045 \\
.800,0 \\
0 \\
\end{array}$ \\
\hline & - Truss C- $75,0.75$ & & & & \\
\hline & - Reng R.33-0.45 & & & & \\
\hline
\end{tabular}

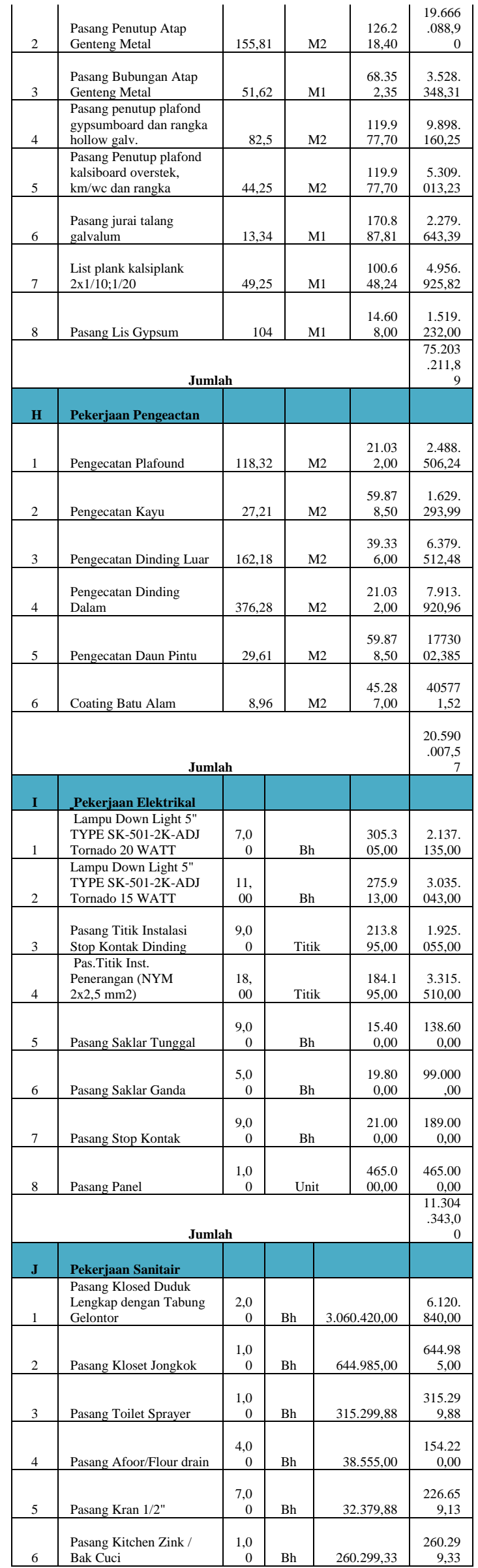




\begin{tabular}{|c|c|c|c|c|c|}
\hline 7 & $\begin{array}{l}\text { Pasang Kran Kitchen } \\
\text { Zink }\end{array}$ & $\begin{array}{r}1,0 \\
0\end{array}$ & $\mathrm{Bh}$ & $225.000,00$ & $\begin{array}{r}225.00 \\
0,00 \\
\end{array}$ \\
\hline 8 & $\begin{array}{l}\text { Pasang Pipa PVC dia } \\
1 / 2^{\prime \prime}\end{array}$ & $\begin{array}{r}37, \\
38 \\
\end{array}$ & M1 & $20.578,80$ & $\begin{array}{r}769.23 \\
5,54 \\
\end{array}$ \\
\hline 9 & $\begin{array}{l}\text { Pasang Pipa PVC tipe D } \\
\text { dia 2" }\end{array}$ & $\begin{array}{r}6,0 \\
5 \\
\end{array}$ & M1 & $32.458,80$ & $\begin{array}{r}196.37 \\
5,74 \\
\end{array}$ \\
\hline 10 & $\begin{array}{l}\text { Pasang Pipa PVC tipe D } \\
\text { dia 3" }\end{array}$ & $\begin{array}{l}32, \\
81\end{array}$ & M1 & $49.907,55$ & $\begin{array}{r}1.637 . \\
466,72\end{array}$ \\
\hline 11 & $\begin{array}{l}\text { Pasang Pipa PVC tipe D } \\
\text { dia 4" }\end{array}$ & $\begin{array}{r}25, \\
05\end{array}$ & M1 & $73.296,30$ & $\begin{array}{r}1.836 . \\
072,32\end{array}$ \\
\hline 12 & $\begin{array}{l}\text { Pasang Septictank } \\
\text { Biofilter kap. } 1,5 \mathrm{~m}^{3}\end{array}$ & $\begin{array}{r}1,0 \\
0\end{array}$ & Unit & $5.536 .000,00$ & $\begin{array}{r}5.536 . \\
000,00\end{array}$ \\
\hline \multicolumn{5}{|c|}{ Jumlah } & $\begin{array}{r}17.922 \\
.453,6 \\
4\end{array}$ \\
\hline \multicolumn{5}{|c|}{ Total Keseluruhan Pekerjaan (Rp.) } & $\begin{array}{r}375.49 \\
3.087 \\
70 \\
\end{array}$ \\
\hline \multicolumn{5}{|c|}{ Ppn (10\%) } & $\begin{array}{r}37.549 \\
.308,7 \\
7 \\
\end{array}$ \\
\hline \multicolumn{5}{|c|}{ Total Keseluruhan Pekerjaan (Rp.) + Jumlah Ppn (10\%) (Rp.) } & $\begin{array}{r}413.04 \\
2.396 \\
47\end{array}$ \\
\hline
\end{tabular}

Hasil akhir dari penelitian menunjukan bahwa perhitungan biaya pembangunan Rumah Dinas Type 90 dengan menggunakan Metode SNI sebesar Rp 434.036.466,44, sedangkan hasil estimasi biaya menggunakan Perhitungan Menurut Kontraktor Rp 413.042.396,47, untuk selisih Anggaran Biaya Pembangunan Rumah Dinas Type 90 adalah sebesar Rp 20.994.069,97. Adapun persentase selisih Metode SNI dengan Hitungan Kontraktor sebesar 4,83\%. Jadi Perhitungan Menurut Kontraktor lebih ekonomis dibandingkan Perhitungan berdasarkan Metode SNI. Dari perbandingan diatas Rencana Anggaran Biaya Metode SNI dengan Perhitungan Kontraktor didapati Rencana Anggaran Biaya Perhitungan Kontraktor lebih rendah, karena harga bahan, upah, overhead, dan koefisien dari kontraktor lebih kecil daripada Metode SNI.

Strategi / upaya yang dilakukan oleh Kontraktor untuk membuat Rencana Anggaran Biaya agar tetap rendah Harga Satuan Pekerjaan adalah dalam menghitung harga satuan pekerjaan di lakukan perhitungan dengan lebih teliti, khususnya pemilihan metode perhitungan yang tepat sehingga di dapatkan anggaran biaya yang ekonomis serta dapat dipertanggung jawabkan, dan kontraktor biasanya mencari harga upah dan bahan yang berada didekat lokasi Proyek untuk menghindari biaya transportasi yang besar. Metode yang di gunakan kontraktor haruslah jelas dan mengikuti Standar yang sudah ditetapkan, tidak dengan metode BOW karena sekarang metode yang sudah menjadi Standar adalah metode SNI, sehingga hasil yang di peroleh dapat di pertanggung jawab kan

\section{SIMPULAN}

Hasil analisis perhitungan rencana anggaran biaya pembangunan Rumah Dinas Type 90, diperoleh anggaran biaya dengan Metode SNI sebesar Rp 434.036.466,44 dan Metode Perhitungan menurut Kontraktor sebesar Rp 413.042.396,47. Selisih harga dari perhitungan dengan menggunakan metode SNI dengan perhitungan menurut Kontraktor sebesar Rp 20.994.069,97, dan untuk persentase selisih perhitungannya adalah sebesar 4,83\%. Sehingga Perhitungan Anggaran Biaya Menurut Kontraktor lebih ekonomis dibandingkan dengan Metode SNI

\section{DAFTAR PUSTAKA}

Ervianto, I, Wulfram, "Manajemen Proyek Konstruksi Edisi-Revisi”, Yogyakarta. Andi, 2005.

Dwipura, I, “Analisis Perbandingan Perhitungan Anggaran Biaya Metode BOW (Burgeslike Openbure Werken) dengan Metode SNI (Standar Nasional Indonesia)", Jurusan Teknik Sipil dan Perencanaan Universitas Bung Hatta Padang, 2014.

Ibrahim, B. H., "Rencana dan Estimate Real Of Cost", Jakarta, PT Bumi Aksara, 2015.

Pastiarsa, M, "Manajemen Proyek Konstruksi", Yogyakarta. Teknosain, 2015.

Sastraatmadja, S, ” Analisa (Tata Modern) Anggaran Biaya Pelaksanaan Lanjutan”, Nova, 1994. 
Soedradjat, S, "Analisa (Tata Modern) Anggaran Biaya Pelaksanaan", Bandung, Nova, 1984.
Pedoman SNI (Standar Nasional Indonesia),

http://www.google,co.id,21/5/2018. 